\title{
Monitoring guidelines for home and outpatient parenteral antibiotic therapy
}

\author{
Alain Y Martel MD CSPQ FRCPC
}

\begin{abstract}
AY Martel. Monitoring guidelines for home and outpatient parenteral antibiotic therapy. Can J Infect Dis 2000;11(Suppl A):35A-44A.

When prescribing home intravenous antibiotic therapy (HIVAT), physicians must consider not only the factors normally considered in a hospital setting, but also the limitations and advantages of home therapy. Examples include dosage schedule, short and long term toxicity, stability of the antibiotics at room temperature after dilution, half-life of antibiotics, compatibility with other antibiotics or medications in the same bag and distribution methods from the supplier (pharmacy) to the patient. Consideration of these factors may direct antimicrobial choices, the mode of delivery and treatment schedule. Other prerequisites for antibiotic selection for home therapy include tolerability and low incidence of toxic reactions. Physicians and nurses must be aware of the adverse effects associated with prolonged outpatient intravenous antimicrobial therapy. Additional knowledge must include pharmacokinetics (absorption, distribution and elimination) and the pharmacodynamics (biochemical and physiological effects and mechanisms of action) of the commonly used antibiotics.

One simple guideline is the less often a drug has to be administered, the more convenient the therapy will be for the patients, facilitating a higher rate of compliance. The less frequent administration schedules will also require less staff time for training and troubleshooting. Many antimicrobial agents can be given once daily and, therefore, readily meet this objective. Classes of antimicrobials that can be used once daily include aminoglycosides, ceftriaxone, vancomycin and the new quinolones.

The development of antimicrobials that can be administered less often has been a major factor contributing to the growth of HIVAT. If an antibiotic has to be used more frequently than three times a day, the use of a computerized ambulatory infusion pump is helpful; however, pumps are expensive and not readily available. Other considerations for HIVAT include renal impairment, liver failure and hematological toxicities. These factors have led the author and colleagues to develop specific monitoring recommendations and techniques.
\end{abstract}

Key Words: Guidelines; Outpatient antibiotic therapy; Parenteral antibiotic therapy

\section{Directives pour la surveillance de l'antibiothérapie parentérale ambulatoire à domicile}

RÉSUMÉ: Lorsqu'ils prescrivent une antibiothérapie intraveineuse administrée à domicile, les médecins doivent tenir compte non seulement des facteurs qui entrent normalement en jeu dans le contexte hospitalier, mais également des limites et avantages du traitement à domicile. Mentionnons entre autre le schéma posologique, la toxicité à longue et à brève échéances, la stabilité des antibiotiques à la température ambiante après leur dilution, la demi-vie des antibiotiques, leur compatibilité avec d'autres antibiotiques ou médicaments dans un même sac et leur accessibilité (de la pharmacie aux patients). Tous ces facteurs peuvent orienter le choix de l'antibiotique, du mode d'administration et du schéma posologique. Parmi les autres préalables au choix de l'antibiotique pour un traitement à domicile, mentionnons la tolérabilité et la faible incidence des réactions toxiques. Les médecins et les infirmières doivent connaître les réactions indésirables de l'antibiothérapie intraveineuse de longue durée à

voir page suivante

Microbiologiste-infectiologue, interniste, Professeur agrége de clinique, CHUC Centre Hospitalier de l'Université Laval, Laboratoire de Microbiologie, Service d'infectiologie, Sainte-Foy, Québec

Correspondence and reprints: Dr Alain Y Martel, Centre Hospital de l'Université Laval, 2705 boul. Laurier, local J-763, Sainte-Foy, Québec G1V 4G2. Telephone 418-656-4141, fax 418-654-2283, e-mail alain.martel@mcb.ulaval.ca 


\begin{abstract}
domicile. Ils doivent en outre connaître la pharmacocinétique (absorption, distribution et élimination) et la pharmacodynamie (effets biochimiques et physiologiques et mécanismes d'action) des antibiotiques d'usage courant.

La règle d'usage est que moins un médicament doit être administré souvent, plus le traitement est commode pour le patient et meilleure sera l'observance thérapeutique. Des schémas posologiques moins fréquents requièrent en outre moins de maind'œuvre pour la formation et la résolution des problèmes. De nombreux antibiotiques peuvent être administrés une fois par jour et répondent donc à ce critère. Les classes d'antibiotiques qui peuvent être utilisés une fois par jour sont les aminosides, la ceftriaxone, la vancomycine et les nouvelles quinolones.

La mise au point d'antibiotiques qui peuvent être administrés moins souvent a été un facteur important pour la multiplication des programmes d'antibiothérapie à domicile. Si un antibiotique doit être utilisé plus souvent que trois fois par jour, il est préférable de recourir à une pompe à perfusion. Or, ces pompes sont coûteuses et difficilement accessibles. Lorsqu'il est question d'antibiothérapie à domicile, il faut en outre tenir compte de la présence d'insuffisance rénale, d'insuffisance hépatique ou de toxicité hématologique. Ces facteurs ont mené l'auteur et ses collègues à mettre au point des recommandations et des techniques de surveillance spécifiques.
\end{abstract}

$\mathrm{O}$ utpatient services are not a recent introduction in Canada but have developed slowly. The search for alternative solutions to hospitalization began in 1971 (1); day surgery received a positive assessment in 1982 (2). Next, to relieve overcrowding of emergency rooms, in 1988 the Quebec Ministry of Health gave new impetus to the development of outpatient therapy by promoting the expansion of intensive care at home and an experimental, home-hospital program (3). As part of the Health Care Reform Act and in the context of the current economic climate, specialized outpatient treatment is now seen as an innovative alternative to hospitalization because of its potential for reducing the pressure on acute care beds and emergency rooms. Additionally, home intravenous antibiotic therapy (HIVAT) offers a significant cost effective alternative to hospitalization. Despite the promotion of this concept to the public by the media and the medical community, HIVAT is being implemented slowly in the province of Quebec. This is due to the complexity of the treatment regimens of health care delivery, the education of home care givers, the availability of drugs and technical devices to allow home treatment and several other factors. There is a lack of consistent, approved financial resources to support many of the provincial programs. Finally, until recently, a serious shortage of published data documenting HIVAT's effectiveness and the absence of effective promoters in the decisionmaking positions (political and medical) have hindered the process.

Since the early 1970s, approaches have been evaluated to facilitate the home treatment of patients who are generally in good health but who require intravenous antibiotics. Home parenteral therapy can free up acute and long term hospital beds, and other resources, including nurses, pharmacists, physicians and supplies, etc. This approach can also fulfill some of the emotional, psychological and physical needs of patients, who usually wish to return to the home and family support as soon as possible.

HIVAT is no longer considered an experimental form of care. It is now being integrated and consolidated into patient care because of the benefits of new developments in intravenous drugs and new technologies for administration. This trend promotes multidisciplinary care and encourages individuals to assume responsibility for their own health. Several different models of delivery with different degrees of autonomy, long term care and patient skills are being employed. These models almost always demonstrate considerable cost savings. Other configurations combining elements from more than one model include self-administration of intravenous antibiotics, daily treatment at a medical day unit or outpatient consultation, the use of electronic pumps and specialized nursing care at home. The initial objective of these models for home care treatment is the same: to avoid or reduce the length of hospitalization while effectively and safely treating a maximum number of patients and types of infectious diseases.

The services, costs and components available from province to province, and within provinces, can vary quite significantly. Patient selection criteria, and the desires, capability and skills of each patient and/or caregiver must be considered when selecting the mode of delivery of treatment at the home.

\section{HIVAT IN QUEBEC}

In Quebec, a program called ATIVAD (AntibioThérapie IntraVeineuse à Domicile) home intravenous antibiotic therapy has been created for the specialized treatment of specific infectious diseases. In the program, antibiotics are administered by parenteral infusion through a peripheral or central venous catheter; therapy is monitored and adjusted as needed based on the patient's initial condition and/or changes in the patient's condition until the desired outcome is achieved. The program provides medical follow-up and a protocol for specialized care that has traditionally required hospitalization.

A wide range of diseases can be treated by the program. The main types of conditions for which ATIVAD is considered appropriate are: bone and soft tissue infections; genitourinary infections; ear, nose and throat infections; lung infections; endovascular infections; infections of joint or endovascular prostheses; and a number of opportunistic bacterial infections associated with AIDS or other viral infections. These diseases are classified by the length of required treatment, ie, treatments requiring four to six weeks or more of intravenous antibiotic therapy, repetitive treatment for chronic diseases and short term repetitive treatment.

Outpatient intravenous antibiotic therapy is now considered to be safe and effective as long as potential patients are properly selected and care providers have clearly defined roles and responsibilities. This reduces the likelihood of treatment failure, including failure from noncompliance. The consequences of failure can be quite serious if they occur in the home setting rather than the hospital.

Outpatient care costs less than traditional hospitalization; however, this must be viewed in the context that most home 
TABLE 1

Typical ATIVAD (antibiothérapie intraveineuse à domicile) care episode

\begin{tabular}{lcccc}
\hline & $\begin{array}{c}\text { Start of } \\
\text { intravenous } \\
\text { treatment }\end{array}$ & Stability & $\begin{array}{c}\text { Discharge } \\
\text { from hospital }\end{array}$ & $\begin{array}{c}\text { of } \\
\text { intravenous } \\
\text { treatment }\end{array}$ \\
\hline Emergency outpatient clinic & $\begin{array}{c}\text { Hospitalization or } \\
\text { ambulatory care unit }\end{array}$ & $\begin{array}{c}\text { Transition between hospital } \\
\text { and home }\end{array}$ & Outpatient treatment & Home \\
\hline
\end{tabular}

care studies are, to some extent, performed with the objective of justifying and promoting the programs. Cost estimation methods, small numbers of patients, absence of controlled random tests, few comparative studies and a large variability of illnesses complicate assessment. When cost studies from other countries or other Canadian provinces are applied to the province of Quebec system, their validity may be questionable. Thus, potential benefits may not be fully or fairly evaluated. For example, there may be a financial advantage for an American hospital that is reimbursed on a case by case basis to be able to divide each episode of intravenous antibiotic therapy into two parts, reimbursable costs according to Drug Utilization Research Group (DURG) rates and different types of insurance coverage. In a country such as Canada, this approach does not demonstrate a clear cost savings for the health care globally. It can, however, be a more efficient way of rendering the same service for certain hospitals, especially if they can then reallocate the resources recovered.

In the United States, the patient must often pay some part of the treatment because outpatient intravenous antibiotic therapy is rarely fully reimbursed, except by health maintenance organizations. Whether the patient and his or her family takes full responsibility for treatment and monitoring varies with programs and depends on the patient's condition. This may require a major investment of time, motivation and education by the patient's caregivers.

In the Canadian health care system, alternatives to hospitalization may require just as great a financial investment from patients. The patient's health, ability to perform the treatment activities, good communication with the health care team and socioeconomic status are often as important in Canada as in the United States to ensure successful home care treatment. Patient selection criteria may become restrictive, and only a small percentage of the patients that could take advantage of home intravenous antibiotic therapy would be eligible.

Thus, the economic potential of ATIVAD is difficult to measure; however, based on the results to date in Quebec, it is considered to be efficient, cost effective and extremely beneficial to those patients who fulfill the entry criteria. However, this type of care may only be achieved in certain areas (regions or sub-regions) that already have the resources, size and volume of potential users. As evaluations of regional needs are undertaken, some situations may require the reallocation of resources and/or new investment.

\section{THE CENTRE HOSPITALIER DE L'UNIVERSITÉ LAVAL ATIVAD PROGRAM}

A HIVAT service has existed at the Centre Hospital de l'Université Laval (CHUL), Quebec for the past 17 years (since
1983). It was introduced as a pilot experiment subsidized by the pharmaceutical industry, then funded by the National Program on Research and Development in Health (NPRDH No 6605-2840 and 6605-2841) as part of a prospective evaluation. This service has nevertheless maintained the concept of HIVAT in Quebec. Because ATIVAD overlaps two ways of care delivery to patients (ie, hospitalization and home health care), the service has gone through a difficult process finding a place within the current structure of the Quebec health care delivery system. Medical diagnostic, therapeutic and technological expertise cannot be provided outside the hospital because once patients were released, they could no longer benefit from the hospital-based financial coverage and in-hospital follow-up to allow them to carry on their intravenous treatment at home. Quebec's home health care services are becoming overloaded, and are technologically and financially unprepared to take on this challenge. One option was the establishment of a multidisciplinary integrated ATIVAD intravenous antibiotic therapy service(s) or teams in Quebec that would comprise specially trained ATIVAD physicians, hospital and home care nurses, pharmacists, and a regional coordinator from the Régie Régionale de la Santé et des Services Sociaux. This would resolve the problems created by the isolation of the existing administrative and functional structures.

ATIVAD was initially conceived as a specialized outpatient service that would incorporate specialized treatment protocols, usually dispensed in an acute care unit. Its goal was to shorten or avoid acute care hospitalization while providing patients with the services required for the treatment of their condition in their own home as quickly as possible and to encourage patients to take a greater responsibility for their own treatment.

The home care protocols mainly consist of clinical procedures and activities performed by health care professionals for specific diseases. Care protocols can be either explicit or implicit. ATIVAD substantially changes a patient's care protocol by moving some of the care activities outside the care unit or hospital and by fully involving the patient or the care giver(s) in activities previously designated for health care professionals.

The development of alternatives to hospitalization is based on the ability to offer a treatment protocol of equivalent quality, safety and effectiveness at home, from both the perspective of care professionals in the hospital, and patients and their families.

The care episode is considered the period of time during which a patient is being treated for one or more health problems, either in a hospital or at home (Table 1). A condition or disease episode potentially treatable at home usually begins with a hospital or ambulatory care unit admission, during 
TABLE 2

Criteria used to assess potential patients for Quebec ATIVAD service

Clinical criteria
- Stability of the infectious disease (fever-free for five days)
- Clinically acceptable response to current antibiotic therapy
- Access to a safe and stable venous access
- Patient/client/caregiver motivation and confidence in abilities to
perform all activities of the ATIVAD home care program
- Emotional stability of patient/client
- Positive mental attitude of all involved at home
- Confidence by team that there will be full compliance
- Absence of history of suicide or drug abuse
- Absence of psychological illness
- Understanding of activities
- Verified ability to perform ATIVAD activities
- Visual, manual and communication skills
- Availability of a relative or friend for support
- Support from family
- Stable, healthy home environment
- Refrigerator with freezer

which an infectious disease is diagnosed. Intravenous antibiotic therapy is then initiated and may be adjusted with the results of diagnostic tests performed. Once the clinical condition has been stabilized, the patient may be discharged from the hospital and treatment can be continued on an outpatient basis until the patient is cured or returns to their normal status. Some variations of this model exist: the patient may not be hospitalized but may be immediately assigned to an ATIVAD program, or may be seen on an outpatient basis and/or in emergency room and then referred to an ATIVAD program directly.

Intravenous antibiotic therapy treats an infection caused by an identified or suspected microorganism. Treatment consists of dosage regimens of antibiotics that are administered intravenously using a venous catheter following a predefined care protocol, dosage and schedule. It also includes follow-up of the patient's condition and the course of the illness until cure. The treatment protocol for an infectious disease consists of various clinical activities or groups of activities performed under the guidance of the professional involved during the care episode. These activities are designed with the following in mind: the special features of the patient's or client's disease, patient or caregiver capabilities; overall patient condition; and, within the context of the special features of the ATIVAD criteria, guidelines and/or caregiver or patient capabilities (Table 2). The care protocol is part of the time line in Table 1.

\section{STEPS IN PLACING A PATIENT INTO A HOME CARE PROGRAM}

Admission to discharge from the care unit or hospital: Following the decision of the attending physician, the patient is
TABLE 3

Criteria used by the Quebec ATIVAD for the selection of antibiotics in a home intravenous program

- Spectrum of activity of the antibiotic

- Penetration of the antibiotics into the infected site

- Pharmacokinetics of the antibiotic, such as extended half-life, etc

- Absence of, or insignificant systemic or local side effects, of the antibiotic

- Compatibility with other antibiotics and heparin

- Stability of the antibiotic at room temperature or refrigerator temperature once diluted

- Ease of preparation and storage

- Evaluation of the patient's or client's ability to use the antibiotic (initially under supervision before leaving hospital and then on their own)

- Cost effectiveness ratio of hospitalization, care, etc, compared with home care

admitted to the hospital or ambulatory care unit. Diagnostic tests are conducted to confirm the preliminary diagnosis. These tests can be completed or repeated at various times during the hospitalization, depending on the patient's status. Intravenous antibiotic therapy is initiated on the basis of clinical and microbiological evidence. The efficacy of the antibiotic is confirmed by repeated diagnostic tests, and by following the patient's general condition and clinical signs of infection.

After observing the clinical course over several doses, the acute clinical phase ends and the patient's condition is considered stable. A patient is considered to be in a stable condition when he or she is well enough to be considered capable of leaving the acute care unit to continue intravenous treatment at home. When eligibility has been established and the patient has consented, training is provided. With confirmation of the patient's knowledge of their responsibilities and home care program, they can be discharged from the hospital to their home. Discharge is approved only if all criteria elaborated by the ATIVAD's team are met (Table 2).

Discharge from the acute or hospital care unit to a home treatment program: Intravenous antibiotic therapy is continued at home, and the focus is shifted to the patient and family. Follow-up is provided by the home care nurses on the multidisciplinary team. The elements listed below are the main features that distinguish the care protocol for the hospitalized patient from one treated at home.

Selection criteria: Rigorous selection criteria are necessary. The eligibility criteria for the Quebec ATIVAD service include clinical, psychological, technical and socioeconomic status. The patient or client, or a member of the family, who undertakes the responsibility to administer the treatment, must also satisfy certain criteria that are assessed by the ATIVAD nurse, pharmacist and physician (Table 2).

The selection criteria must always be checked and patient eligibility determined by the professionals from the multidisciplinary team. The physician must evaluate the medical, clinical criteria, while the assessment of the other criteria is shared by the other members of the team.

Selection of the antibiotic: The choice of an antibiotic is made by the attending physician after having made the diagnosis of 
TABLE 4

Serious adverse events related to home intravenous antibiotic therapy (6-13)

\begin{tabular}{lcc}
\hline Events & Antimicrobials & Comments \\
\hline Rash & Vancomycin & $\begin{array}{c}\text { Maculopapular, urging } \\
\text { treatment to be } \\
\text { Cephalosporins } \\
\text { Penicillins }\end{array}$ \\
& Clindamycin & \\
& Gancyclovir & \\
Anaphylaxis & Penicillins & Usually delayed onset \\
& Cephalosporins & \\
Granulocytopenia & Penicillins & Less than 500 \\
& Cephalosporins & granulocytes/mL \\
& Vancomycin & \\
Fever & Vancomycin & Fever followed by rash \\
& Cephalosporins & \\
Diarrhea & Penicillins & \\
Hearing loss & Cephalosporins & Severe, Clostridium \\
& Aminoglycosides & \\
\hline
\end{tabular}

TABLE 5

Antimicrobial pharmacodynamics and dosing regimens (6-13)

\begin{tabular}{|c|c|c|}
\hline Antibiotic & Pharmacodynamics & Regimen's goal \\
\hline $\begin{array}{l}\text { Penicillins } \\
\text { Cephalosporins }\end{array}$ & $\begin{array}{l}\text { Bactericidal at } \\
\text { minimal } \\
\text { concentration; } \\
\text { brief and no PAE }\end{array}$ & $\begin{array}{l}\text { Maximize exposure time; } \\
\text { keep serum levels } \\
\text { greater than MIC }\end{array}$ \\
\hline $\begin{array}{l}\text { Imipenem } \\
\text { Vancomycin } \\
\text { Clindamycin } \\
\text { Macrolides }\end{array}$ & $\begin{array}{l}\text { Bactericidal at } \\
\text { minimal } \\
\text { concentration; } \\
\text { prolonged PAE }\end{array}$ & $\begin{array}{l}\text { Maximize exposure time; } \\
\text { serum levels can fall } \\
\text { below MIC }\end{array}$ \\
\hline $\begin{array}{l}\text { Aminoglycosides } \\
\text { Quinolones } \\
\text { Metronidazole }\end{array}$ & $\begin{array}{l}\text { Bactericidal at high } \\
\text { concentration; } \\
\text { prolonged PAE }\end{array}$ & $\begin{array}{r}\text { Maximize concentration; } \\
\text { attain peak serum level }\end{array}$ \\
\hline
\end{tabular}

MIC Minimal inhibitory concentration; PAE Postantibiotic effect

the infectious disease causative organism. The effectiveness of the drug against the pathogen is the most important factor in selection. Other factors to be considered in a home treatment context can be found in Table 3 .

Selection of the most appropriate antibiotic is an increasingly complex task. In a hospital setting, infectious disease consultation and the pharmacist help determine appropriate treatment.

The physician also specifies the dosage, taking into account the pathogen, site of infection, the condition of the patient and the type of care selected. Thus, for home treatment, the physician must choose the most effective pharmaceutical product that will provide: the greatest ease of usage and efficacy; the patient or client with the optimal dosage schedule and administration method; and an overall program that will readily fit in with the family's lifestyle. The antibiotic's side effects must also be known and predictable (Table 4). Thus, the antibiotic must not only be active against the pathogen
TABLE 6

Half-lives of the most common parenteral antimicrobials (6-13)

\begin{tabular}{lc}
\hline Drug & Half-life (hours) \\
\hline Acyclovir & 2.5 \\
Aminoglycosides & $2-3$ \\
Cefazolin & $1-2$ \\
Ceftriaxone (Rocephin, Hoffmann-La Roche & $5.5-11$ \\
$\quad$ Limited, Mississauga, Ontario & $3-5$ \\
Ciprofloxacin (Cipro, Bayer Inc, Toronto, & \\
$\quad$ Ontario) & $2-3$ \\
Clindamycin (Dalacin C, Pharmacia \& Upjohn & \\
$\quad$ Inc, Mississauga, Ontario) & $14-25$ \\
Doxycycline & 2.9 \\
Gancyclovir (Cytovene, Hoffmann-La Roche & \\
$\quad$ Limited) & $6-8$ \\
$\quad$ Levofloxacin (Levaquin, Janssen-Ortho Inc, & \\
$\quad$ Toronto, Ontario) & $6-14$ \\
Metronidazole & $4-6$ \\
Vancomycin &
\end{tabular}

but must also provide an acceptable level of tolerance for the patient in a home environment (Tables 5-7).

Determination of the venous route: The choice of venous route is a medical decision that is mainly a function of the required duration of treatment and the condition of the patient's veins at the most easily accessible and appropriate sites. The insertion and maintenance of a peripheral catheter assumes that the patient has healthy, viable and accessible veins to facilitate the regular changes of site usually required. It also assumes that careful monitoring can be assured either by the patient and the patient's family or by the health care team in hospital follow-up visits. This is necessary to minimize the side effects that occur most frequently with peripheral catheters, eg, infiltration, thrombosis, etc. Although less often used, the central venous catheter is preferred when the quality and accessibility of the patient's peripheral veins are poor and the treatment is to be for a long period of time, or if any changes in the site could pose any expected or possibly unforeseen problems. The central venous catheter is inserted as a more permanent device and provides some obvious advantages. For example, when persistent problems recur with some peripheral catheters, they may be replaced by a central catheter.

The physician selects the venous route so as to minimize any future or potential complications. These can include the following: infiltration; thrombophlebitis; infection at the puncture site; and accidental displacement of a forearm catheter or one in another peripheral site. Complications associated with a central catheter are less frequent but can be more serious. The main complication, air embolism, requires intervention by a medical team. Thrombosis and rupture of the central catheter are also possible.

New types of catheters, such as the peripherally inserted central catheter (PICC), have received favourable reviews from the outpatient medical community. Some of the advantages of the PICCs are the stability and sustainability of the central catheter during insertion, which help to avoid many of the se- 
TABLE 7

Recommended laboratory monitoring for patients on home intravenous antibiotic therapy (6-13)

\begin{tabular}{|c|c|c|}
\hline Antibiotics & $\begin{array}{l}\text { More frequent } \\
\text { side } \\
\text { effects }\end{array}$ & Monitoring \\
\hline Penicillins & $\begin{array}{c}\text { Leucopenia; } \\
\text { interstitial } \\
\text { nephritis; hepatitis } \\
\text { (nafcillin) }\end{array}$ & $\begin{array}{l}\text { CBC and renal function } \\
\text { test* and liver function } \\
\text { test }^{\dagger} \text { once/week }\end{array}$ \\
\hline Cephalosporins & Leucopenia & $\begin{array}{c}\text { CBC once or } \\
\text { twice/week; renal } \\
\text { function* once/week }\end{array}$ \\
\hline Aminoglycosides $^{\ddagger}$ & $\begin{array}{l}\text { Nephro- and } \\
\text { ototoxicity }\end{array}$ & $\begin{array}{l}\text { Renal function* } \\
\text { twice/week; check on } \\
\text { hearing, balance, } \\
\text { dizziness, dosage } \\
\text { once/week }\end{array}$ \\
\hline Vancomycin $^{\ddagger}$ & $\begin{array}{l}\text { Leucopenia; } \\
\text { nephrotoxicity }\end{array}$ & $\begin{array}{c}\text { CBC once or } \\
\text { twice/week; renal } \\
\text { function* twice/week; } \\
\text { check dosage } \\
\text { once/week }\end{array}$ \\
\hline $\begin{array}{l}\text { Clindamycin } \\
\text { (Dalacin C, Pharmacia } \\
\text { \& Upjohn Inc, } \\
\text { Mississauga, Ontario) }\end{array}$ & Hepatotoxicity & $\begin{array}{l}\text { Liver function }^{\dagger} \\
\text { test once/week or less }\end{array}$ \\
\hline $\begin{array}{l}\text { Amphotericin B } \\
\text { (Fungizone, } \\
\text { Bristol-Myers Squibb } \\
\text { Canada Inc, Montreal, } \\
\text { Quebec) }\end{array}$ & $\begin{array}{l}\text { Nephrotoxicity and } \\
\text { electrolyte } \\
\text { disorders }\end{array}$ & $\begin{array}{l}\text { Renal function test* } \\
\text { and electrolytes } \\
\text { twice/week until stable; } \\
\mathrm{Ca}^{++} \text {and } \mathrm{Mg}^{++} \text {once a } \\
\text { weeks }\end{array}$ \\
\hline Foscarnet & $\begin{array}{l}\text { Marrow toxicity; } \\
\text { Nephrotoxicity }\end{array}$ & $\begin{array}{l}\mathrm{CBC}^{*} \text { twice/week and } \\
\text { renal function test* } \\
\text { once a day until stable, } \\
\mathrm{Ca}^{++} \text {and } \mathrm{Mg}^{++} \text {once a } \\
\text { week }\end{array}$ \\
\hline $\begin{array}{l}\text { Gancyclovir (Cytovene, } \\
\text { Hoffmann-La Roche } \\
\text { Limited) }\end{array}$ & $\begin{array}{l}\text { Marrow toxicity; } \\
\text { Nephrotoxicity }\end{array}$ & $\begin{array}{l}\text { CBC twice/week and } \\
\text { renal function* } \\
\text { twice/week until stable }\end{array}$ \\
\hline
\end{tabular}

*Renal function: blood urea nitrogen, creatinine, ions and urinalysis. ${ }^{+}$Liver function test: alanine aminotransferase, aspartate aminotransferase, lactate dehydrogenase, total and direct bilirubin, Quick and cephalin. ${ }^{*}$ These antibiotics can also be dosed on an outpatient basis. CBC Complete blood count

rious side effects encountered with conventional central catheters.

Training in the administration of home antibiotics: Training patients or clients in the activities required to administer their intravenous antibiotics at home is a fundamental role of the service. This activity requires the involvement of the physician, nurse and pharmacist.

\section{INFORMING THE PATIENT}

The administration method taught to the patient and, if possible, to a family member, includes asepsis, preparation of equipment and the antibiotics, as well as the actual administration and storage of equipment and medications. Asepsis preserves the sterility of the medications, administrative process and equipment.

Preparation of the equipment includes instructions on how to lay out all of the materials so that the equipment can be eas- ily reached and available when using them during the actual administration. Reconstitution of the antibiotics is a relatively complicated activity, depending on the types and form in which the drug is supplied, eg, solution in a vial, in an ampoule or minibag, or powder in a vial. A certain amount of dexterity is required to handle the vials, ampoules or minibags. Actual administration includes mounting the minibag on a pole, verification of the permeability of the catheter, perfusion of the antibiotic, rinsing the catheter with sodium chloride and closing with heparin. There are alternative ways to administer antibiotics, such as unidose syringes, infusion pumps, etc. Appropriate storage of medications and supplies is also taught.

Guidelines have been prepared by Martel et al $(4,5)$ that illustrate the various techniques in a simple manner that helps the patient through the complex learning process. Teaching methods vary, of course, according to the antibiotics used, and the equipment and perfusion kit. The use of a programmable pump requires even more sophisticated training, and this training must be adapted to each piece of equipment.

The main elements of the guidelines are: preparation of the antibiotics; preparing the work surface; preparing the equipment; hand-washing; reconstitution and dosing of the antibiotic; handling ampoules or vials; handling the minibag; administration of the antibiotic; assembly of the perfusion kit and minibag; checking the permeability of the catheter; rinsing the catheter; actual administration; clearing the catheter with heparin; storage of the equipment and drugs; monitoring and prevention of complications; handling and obtaining medications; handling and obtaining equipment; handling the catheter; steps to take in case a dose is forgotten; recording data; administration schedule; rinsing the catheter with sodium chloride (normal saline); local complications associated with the catheter, pain, redness, etc; taking one's temperature; information on medical resource personnel available who will continuously be on call (physician, nurse, pharmacist); and follow-up procedures (place, time).

Learning procedures: The patient is trained in the hospital. More training may also be given on an outpatient basis or some at the patient's home. The training activities are completed or consolidated during home nursing visits or follow-up at the hospital or outpatient clinic. When the patient or client has mastered the administration method for the intravenous antibiotics, discharge home is authorized and a discharge plan is created by the nurse. This plan is vital in the context of the patient being able to perform optimum, efficient and safe ATIVAD care at home. The most appropriate time for discharge (ie, after completion of training, a final confirmation that the patient has met all the criteria, etc) is selected to produce the best results in terms of cost and effectiveness and, it is hoped, cure.

Training may be extended when a person has problems learning the procedures. This training should be continued for as long as it is reasonable, assuming that the patient or client is capable and there will be improvement in the execution and/or administration of his or her required activities at home. A patient who cannot successfully complete all the steps in training should remain hospitalized. The period of time devoted to education can extend from one to five days, depend- 
ing on the complexity of the treatments. Usually, it requires one to three days.

A written guide is always given to the patient and family. The guide is a valuable reference throughout the care episode, and is used to record data and observations after each administration (5).

Administration of the medications: In the home selftreatment model, the patient or family member who has mastered the administration technique performs all the steps according to how he or she was taught and the importance of how strictly he or she must follow the dosage schedule.

Administration technique: The daily administration of the medications is performed by the patient or family members, with an electronic pump, a one-dose syringe, by the staff at an outpatient clinic, or by home care nurses. These individuals must master the following elements to perform the activities effectively: asepsis technique; preparation of equipment; reconstitution of antibiotics; mounting of mini-bag and perfusion kit; verification of permeability of the catheter; perfusion of the antibiotic; monitoring of administration; rapid intervention in case of problems; and the storage of required elements.

Administration schedule: Drug administration activities generally require 5 to 90 mins by the patient or family member for each administration. The administration schedule varies from one to four times per day. To facilitate administration by the patient or client, night time (evening) doses are eliminated, so that the administration schedule takes place during usual waking hours, ie, between 06:00 and 23:00. The use of infusion pumps may bypass this problem.

Monitoring problem situations: During the training, the patient or client is made aware of most potential problem situations that may occur with their particular regimen. A written list of potential problem situations is usually given to patients to help them monitor any of these possibilities and help them prevent possible situations during the administration of their medications. Some of the main problems reported include the following.

Side effects of the medications: Some of the most common side effects that occur with home intravenous antibiotics, in order of importance, are thrombophlebitis, skin rashes, complications at the injection site, fever due to drugs, shivering, hot flashes or sweating, leukopenia, pain, nausea, headaches, neutropenia, eosinophilia, thrombocytopenia, nephrotoxicity, ototoxicity, diarrhea, alopecia, vasovagal episode, hemorrhagic cystitis, vestibular damage, ageusia and hematuria (Table 7).

Most of the common side effects for a particular medication are usually already known and readily identifiable, and the usual practice is to inform the patient both verbally and in writing of what he or she should look for that may be related to the drug prescribed.

Problems with equipment: The presence of air bubbles anywhere in the perfusion system is a common problem. The patient must be informed of the necessity of discharging any air from their syringe or tubing before using it to inject or infuse their medication. Blood reflux or back-up into the catheter is another problem that can be solved by immediately irrigating the catheter with a sodium chloride or heparin solution.
TABLE 8

Nursing responsibilities

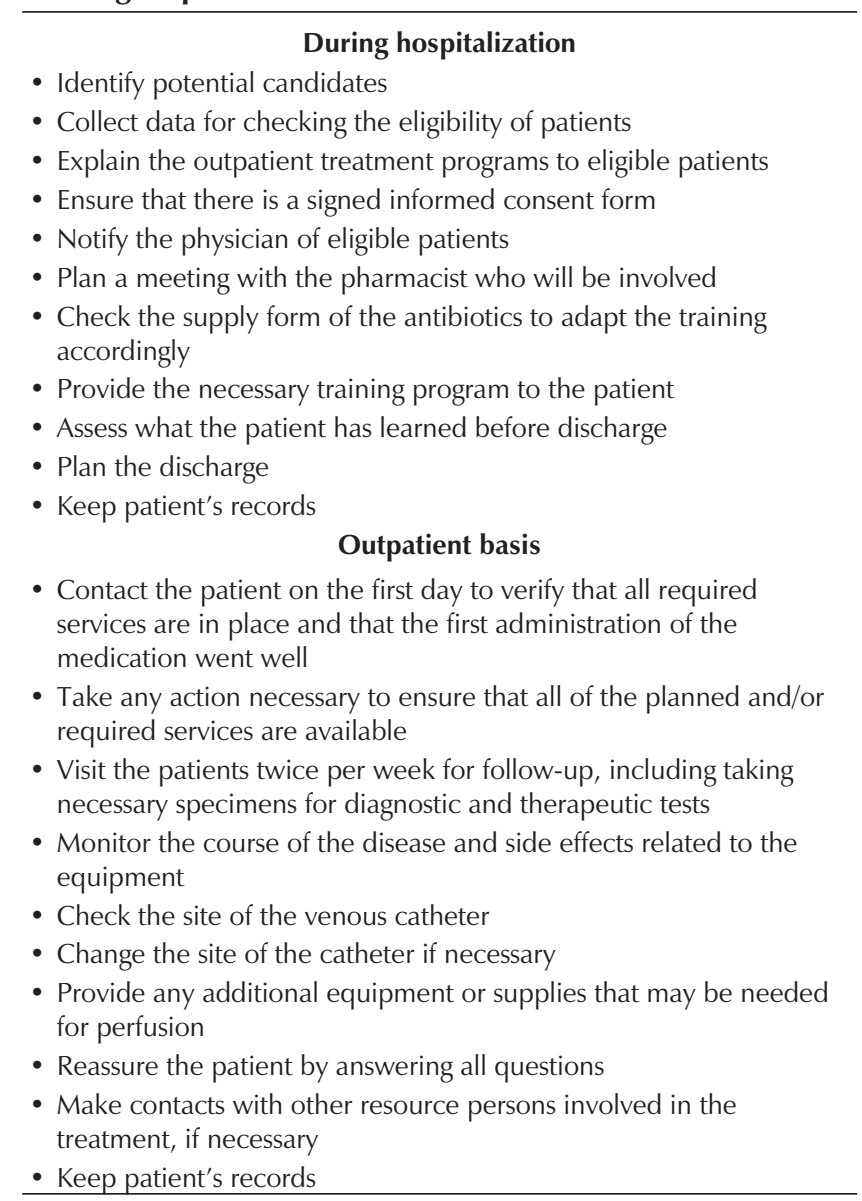

A greater number of infusion problems are associated with peripheral catheters. The most frequent are accidental displacement, blocking or defects in the catheter, infection at the puncture point, thrombophlebitis and infiltration of the solution, which then leaks into the surrounding tissue outside the vein. Assessment of the condition of a central catheter is required once a week by a medical staff member, while the peripheral catheter should be checked at least twice a week.

Follow-up with the patient or client in the outpatient setting: Follow-up of the outpatient care and the patient's status after discharge, and even final discharge from home treatment program, should be performed by a multidisciplinary team, consisting of physicians, nurses and pharmacists. When the distance between the patient's home and the original hospital of admission does not allow for regular visits, this follow-up can be performed by home care nurses, in a doctor's office or at a hospital near the patient's home. In general, most HIVAT provide nursing follow-up every two or three days and medical follow-up once a week, with laboratory tests performed specific to the patient's condition(s) (Table 7). It is, however, important to stress that preparation for all stages of the outpatient episode should begin as soon as the patient is admitted and considered a potential outpatient candidate.

Nursing follow-up: The nurse plays a vital role in coordinating and dispensing specialized outpatient services. In addition 
TABLE 9

Medical follow-up

- Admit the patient

- Determine the diagnosis of an infectious disease

- Prescribe and analyze the necessary diagnostic tests

- Prescribe the most appropriate intravenous antibiotic therapy

- Determine the preferred venous route

- Assess the patient's clinical eligibility for the outpatient program

- Explain the outpatient treatment program to any eligible patient(s)

- Adjust the intravenous antibiotic therapy as needed

- Participate in training the patient and evaluating the patient's knowledge level

- Ensure stability of the underlying disease

- Check the efficacy of the antibiotic

- Track the course of the disease, side effects and complications

- Determine the approximate duration of home treatment

- Issue medical discharge from the hospital care unit

- Keep patient's records

\section{Outpatient basis}

- Track the course of the disease and any complications

- Check the patient's tolerance to the drugs

- Observe and take any required action for any side effects that persist

- Check the venous route and its permeability

- Prescribe and/or change a venous route if needed

- Prescribe and analyze the diagnostic tests necessary for follow-up

- Prescribe any modifications to the intravenous therapy

- Rehospitalize, if necessary

- When cure and/or therapy is complete, discharge the patient from the program

- Keep patient's records

to clinical training, monitoring and assisting in administration activities, the main activities performed by nurses are planning the discharge, communicating with the patient, acting as liaison with other institutions take part in the patient's treatment (as required) and coordinating the necessary human resources in the program. Outpatient follow-up is designed to minimize events that can hinder or negatively influence the feasibility, quality and effectiveness of the home treatment program. The tasks of the nurses responsible for outpatient intravenous antibiotic therapy are described in Table 8 .

Medical follow-up: Medical follow-up is shared among the attending physician at the hospital, the infectious disease specialist and other medical consultants, depending on the disease(s) being treated. The patient's family doctor may also play a role if the distance between the patient's home and the hospital where treatment originated is great. A cooperative arrangement between the clinical departments of the hospital and the treating physicians from the infectious disease service is recommended.

The physician always remains ultimately responsible for treatment of the patient at home. The main medical responsibilities are outlined in Table 9.

The role of the physician in outpatient care is sometimes
TABLE 10

Pharmacological follow-up

During hospitalization
- Conduct a pharmacological analysis of the patient's in-hospital
records
- Establish administration parameters (drug, dosage, schedule,
solution, speed)
- Inform physicians and staff nurses of the analyses
- Prepare the drugs and equipment for the care units
- Prepare the drugs and materials necessary for teaching the patients
- Participate in the training program (sterility, asepsis, special features
of the antibiotics, supplies, method(s) and storage of the
medications)
- Fill out and give the patient the information sheet on the antibiotic
- and heparin roles and administration techniques
Participate in evaluating if patient has a knowledge of the entire
- Track any changes in the parameters or differences in the
prescribed medications
- Monitor side effects of the drugs
- Keep the pharmacology records
- Provide drugs and necessary equipment
- Answer the patient's information needs
- Monitor the development of drug parameters
- Monitor side effects of the drugs

disputed. Questions may be asked about safety, medical responsibility and medicolegal aspects. There should be no doubt that the follow-up on the course of the infection is a medical responsibility and that the physician is the main designee who should follow the patient during all phases of the home-based intravenous treatment.

Pharmacological follow-up: The role of the pharmacist in the home treatment model is also important, and includes certain aspects of important training and follow-up. Sometimes the entire outpatient service may be the responsibility of the pharmacy. The main pharmacological activities are described in Table 10 .

Follow-up by the patient or patient's family: As already discussed, the factor that has changed most in outpatient versus hospital care is the administration of the medication. During a traditional hospital stay, the patient passively submits to treatment. In home treatment, the patient becomes his or her own nurse, physician and pharmacist. That is why the eligibility criteria are important and even somewhat restrictive. The main tasks shifted to the patient in home treatment are: administration of each dose of antibiotic(s); monitoring and administration; monitoring their own general and physical condition; monitoring side effects and complications; traveling for outpatient follow-up; obtaining supplies of drugs and equipment; reporting problems; and keeping their own detailed patient records.

Safety of outpatient intravenous antibiotic therapy: The safety of treatment depends on the selection of good candidates for outpatient antibiotic therapy. Candidates must be motivated, reliable, socioeconomically independent, capable 
of acquiring the necessary knowledge, and becoming sufficiently technically skilled to perform the required activities.

Patient's responsibility: The patient or the patient's family ensures the success of any HIVAT program. Most care and monitoring activities are transferred to the patient or family in the outpatient treatment model. In the self-treatment model, the patient masters administration techniques and regularly administers the antibiotics to him or herself. Moreover, together with the health care team, the patient monitors the entire care episode. The patient is literally responsible for following the instructions to the letter, including compiling statistics on how the treatment progresses and is responsible for contacting any of the resource personnel as soon as any unexpected problems appear. In the beginning, written consent to participate in an outpatient treatment program was required. Now, ATIVAD is considered a standard treatment and no longer requires written consent.

Professional responsibility: Outpatient treatment is a major challenge to the normal course of the professional activities and medical and medicolegal accountability for hospitalized or or even home-treated patients. Thus, the physician must remain very much involved in every aspect of these types of programs and be the professional ultimately responsible for the team. Home treatment implies a more developed role for nursing care, including new case management functions, discharge planning and liaison with the other resources of the health care system. Many programs have assigned this entire program to the pharmacy on an experimental basis.

There does not seem to be a single and unanimously accepted model for the roles of the various professionals. This is also why the question has not been directly addressed in this paper. The functional models that have been presented here are those that have been observed to be the most feasible and viable, given the existing resources and significant variations from city to city and province to province. Variations in resources and support will produce wide variations in costs and efficacy.

\section{ATIVAD EFFICACY}

The true test of the efficacy of the ATIVAD treatment program is its ability to cure the patient. Outpatient intravenous antibiotic therapy can be safe and effective when patients are rigorously selected according to their clinical state and other criteria listed previously, and when they are able to acquire and apply the necessary knowledge. It is also necessary for the care providers to be qualified and have adequate knowledge of the care protocols, equipment and medication currently available.

The few comparative studies available do not report any difference in efficacy between outpatient treatment and treatment in a hospital bed. The patients treated on an outpatient basis cannot be compared fully with those who are hospitalized. In other noncomparative studies, it is asserted that the results must be comparable with hospitalized patients, and any differences cannot be attributed to the variations in the forms of care.

Although side effects and complications are considered similar and independent of the form or place of treatment, the consequences of these complications can differ, depending on whether an episode takes place at home or in hospital. Having the patient under medical and nursing supervision in a hospital bed may result in quite a different outcome in some cases.

Observed cure rate: Only a few outpatient studies report the observed cure rate. This rate is generally less than $100 \%$ but is comparable with the cure rate in hospitals. In essence, no data suggest that the cure rate observed in hospitalized patients is lower than the rate for patients treated on an outpatient basis.

Reported side effects and complications: The main side effects and complications reported with ATIVAD are problems associated with drugs and equipment, and certain complications of the underlying illness. The general conclusion seems to be that side effects experienced by hospitalized patients are equivalent to those of patients treated at home.

Some patient-specific problems have already been mentioned, such as the lack of compliance, dropping out before the end of treatment, taking alcohol during treatment, emotional instability and failure to communicate with team members. The following is a list of the main side effects and complications related to the drugs, materials or underlying illness. (These are classified according to whether they are local or systemic complications.)

Side effects of drugs: The main side effects and problems associated with the medications are: thrombophlebitis, complications at the injection site; skin rashes; fever due to drugs; shivering; heat flashes and sweats; pains; nausea and headaches; diarrhea; ageusia; leukopenia; neutropenia; eosinophilia; thrombocytopenia; nephrotoxicity; ototoxicity; alopecia; vasovagal episode; vestibular damage; hemorrhagic cystitis; hematuria; and the drug's failure to reach the infection site(s).

Problems associated with the equipment: The main problems associated with the equipment are: the presence of air bubbles in the perfusion system; blood reflux in the central or peripheral catheter; accidental shifting or withdrawal of a peripheral catheter; occlusion or defects in the catheter; infection at the puncture point; thrombophlebitis; improper functioning of the catheter; catheter maintenance problems; loss of venous access; and infiltration of the solution, which discharges outside of the vein and into the surrounding tissue.

Complications of the underlying illness: The course of the underlying disease or illness results in exceptional events, such as rehospitalization for surgery or other reasons, change of antibiotics, recurrence of the infection, failure of treatment, and even death.

\section{INNOVATIVE CHARACTERISTICS OF THE QUEBEC ATIVAD PROJECT - RELEVANCE, ADVANTAGES AND DISADVANTAGES}

The development of alternatives to short term hospitalization are encouraged in the current health care context. Beds for acute care have decreased, and, in major urban centres, there are serious problems with overcrowded emergency rooms.

Alternatives to hospitalization are, thus, an innovative and 
high priority project for any health care organization anxious to improve access to short term care and promote greater autonomy for individual patients. Outpatient treatment is favoured not only as a way to increase the current efficiency of the health care system but also as a way to enable individuals to take charge of their own health care. The assumption of responsibility by individuals and their families is facilitated by an accessible and organized structure. ATIVAD allows patients to return to their homes while continuing intravenous treatment and still maintaining the reliability and safety of hospital treatment. The satisfaction of the clientele served by ATIVAD is significant, and their desire to use this approach again, if the need arises, is unanimous. This service promotes self-management adapted to the patient's health, whether young or adult, suffering from single or multiple diseases.

ATIVAD differs from other proposed alternatives because it encourages greater autonomy for the patient and the patient's family. Our program, as part of the study funded by the National Health Research and Development Program, has been exported to at least five other major hospitals in the region.

Any innovative alternative to hospitalization in the current health care system needs the participation of all parties in-

\section{REFERENCES}

1. Loi sure le Santé des Les Services Sociaux, chapter 48, 24 déc. 1971, Statutes of Queébec.

2. Pineault R. Evaluation d'un programme de chirurgie d'un jour, Direction de l'évaluation des programmes, Gouvernement du Québec, Ministère des Affaires sociales. Octobre 1982.

3.. Lavoie-Roux T. Le désengorgement des services d'urgence. Mémoires au conseil des ministres. Ministère de la Santé et des Services Sociaux. Gouvernment du Québec 6 mars 1986.

4. Allaire L, Parent A, Martel AY. Guide for persons involved in the management of patients admitted to the Home Antibitotic Prgoram. Sainte-Foy: Le Centre Hospitalier de l'Université Laval, 1989:1-36.

5. Allaire L, Parent A, Martel AY. Home intravenous antibiotic therapy. Patient and family guide. Sainte-Foy: Le Centre Hospitalier de l'Université Laval, 1989:1-25.

6. Tice AD. Handbook of Outpatient Parenteral Therapy for Infectious Diseases. New York: Scientific American Inc, 1997.

7. Tice AD. Once-daily infusions in outpatient therapy. Infusion 1994;1:7-8. volved. This ultimately allows other programs to be started and/or continued while still providing safe, effective and high quality services. The organization of a multidisciplinary structure such as ATIVAD also requires a desire by the participants to promote and participate, even if on a volunteer basis. Only this type of dedication will help change how health care is provided in Canada.

Other patients may benefit from home therapy. Other forms of dispensing care with less participation by patients or clients in their care, eg, the use of electronic pumps, day medical units, outpatient clinic care, etc, are alternatives to ATIVAD that can allow a more 'complicated' patient or client to return home.

All alternatives to hospitalization imply displacing hospital technology to the home. In the current care context and with the restrictions that have been imposed by various administrative levels, these alternatives often encounter problems of personnel availability and qualifications, a lack of structures that allow for technology transfer from the medical centre to the home, and, above all, financial resources that are inadequate. Such administrative pigeonholing by the system does not facilitate the continuity of patient treatment from hospital to home.

8. Craig WA, Ebert SC. Continuous infusion of B-lactam antibiotics. Antimicrob Agents Chemother 1991;36:2577-83.

9. Holford NHG, Benet LZ. Pharmacokinetics and pharmacodynamics: rationale dose selection and time course of drug action. In: Katzung BG, ed. Basic and Clinical Pharmacology, 6th edn. Norwalk: Appleton and Lange, 1995:38.

10. Benet, LZ, Mitchell JR, Sheiner LB. Pharmacokinetics: the dynamics of drug absorption, distribution and elimination. In: Gilman AG, Rall TW, Nies AS, Taylor P, eds. Goodman and Gilman's The Pharmacological Basis of Therapeutics, 8th edn. New York: Pergamon Press, 1990:27.

11. Beam TR Jr, Brook I, Craig WA, et al. Continuous vs intermittent infusion of B-lactam antibiotics: a potential advance. Infect Med 1992;9(Suppl B): 1 .

12. Craig WA. Kinetics of antibiotics in relation to effective and convenient outpatient parenteral therapy. Int J Antimicrob Agents 1995;5:19-22.

13. Craig WA. Antibiotic selection factors and description of a hospital-based outpatient antibiotic therapy program in the U.S.A. Eur J Clin Microbiol Infect Dis 1995;14:4-10. 


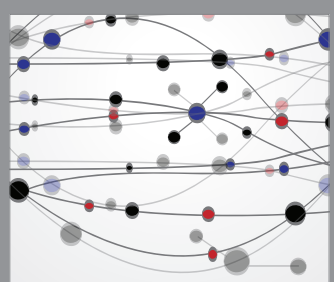

The Scientific World Journal
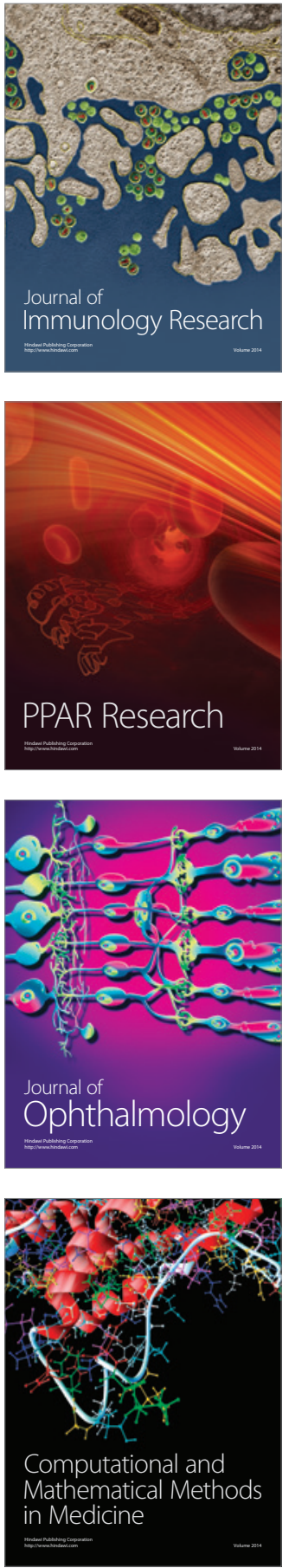

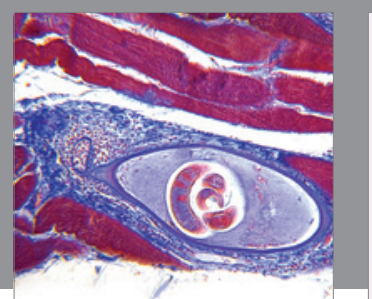

Gastroenterology Research and Practice

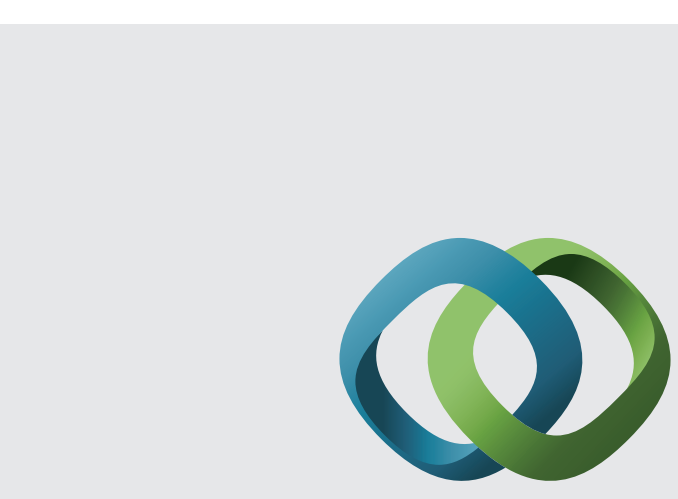

\section{Hindawi}

Submit your manuscripts at

http://www.hindawi.com
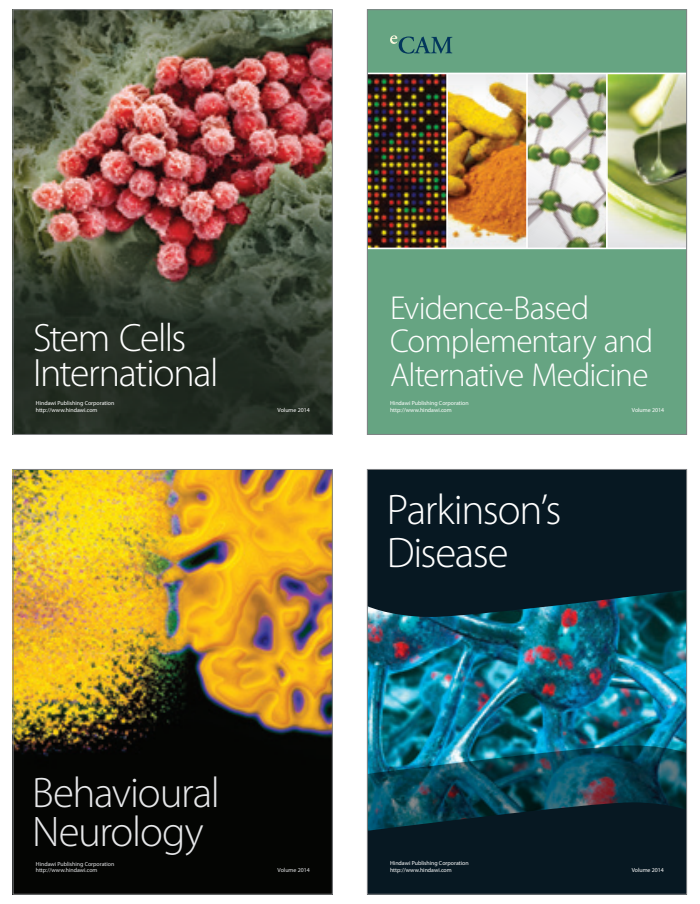
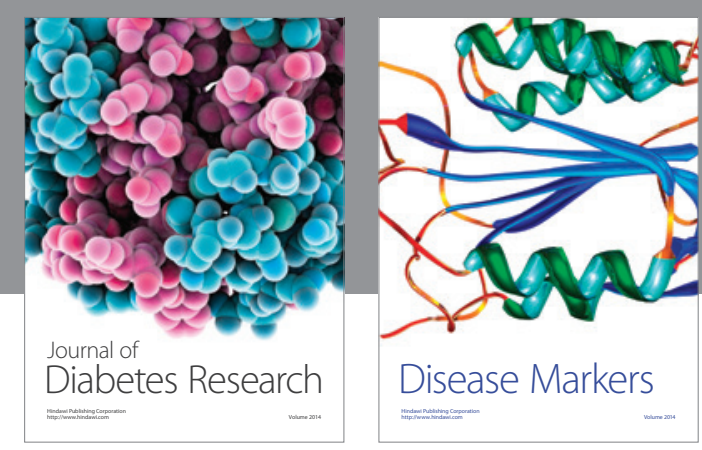

Disease Markers
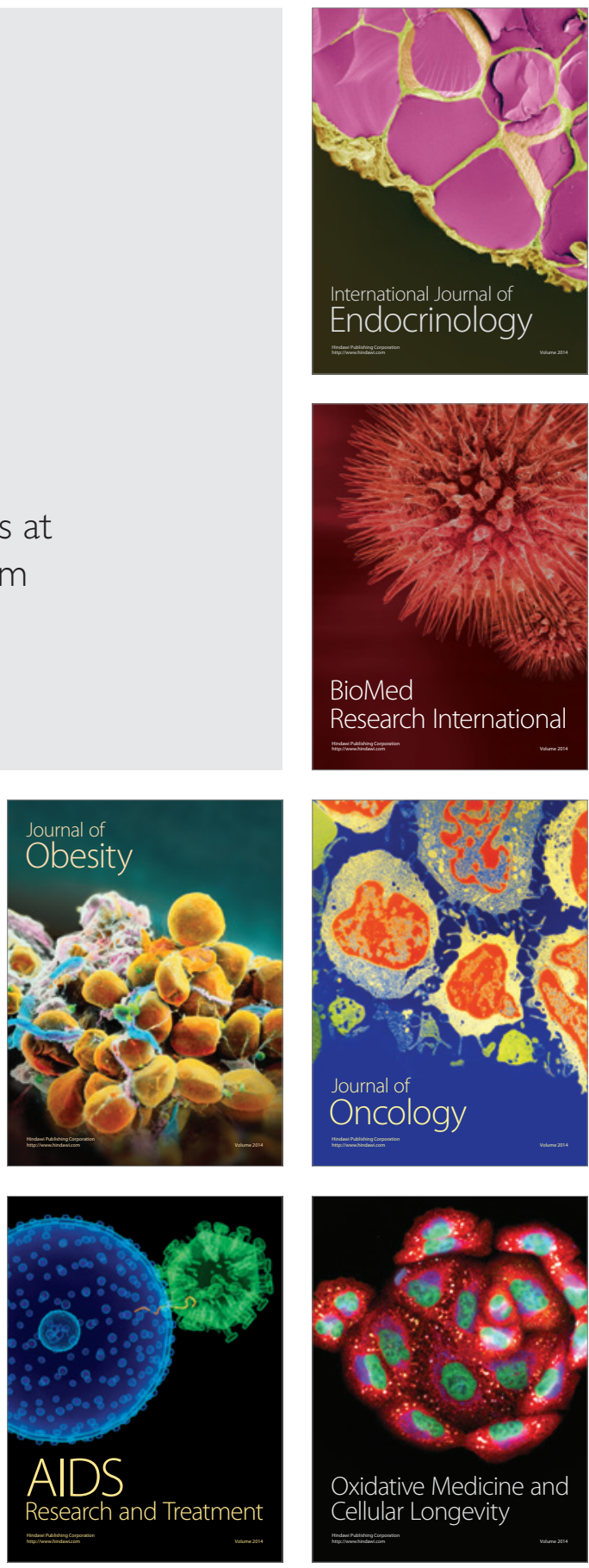